\title{
Comparison of Elliptic Envelope and Isolation Forest Algorithm on Imbalance Dataset
}

\section{Komparasi Algoritma Elliptic Envelope dan Isolation Forest Pada Data Tidak Seimbang}

\author{
Supri Amir ${ }^{1 *}$, Bagas Prasetyo ${ }^{2}$
}

\begin{abstract}
The problem of imbalanced data is important in Data Mining. A dataset with imbalanced classes is a dataset that the event frequency of certain classes is different from other classes. The imbalanced problem gives a bias in the classification performance. Many researchers have developed algorithms and modified the preprocessing stage to overcome the problem. Hence, this research focused on algorithm comparison between One Class Classification algorithms, which are Elliptic Envelope and Isolation Forest, on solving of the imbalanced data. The results showed that the Elliptic Envelope method performed a better performance compared to the Isolation Forest algorithm by giving $80.28 \%$ of recall testing and $80.28 \%$ of precision meanwhile Isolation Forest only giving $46.95 \%$ of recall testing and $46.95 \%$ of precision.
\end{abstract}

Keywords: Data mining, Imbalance Datasets, Classification, Elliptic Envelope, Isolation Forest

\begin{abstract}
Abstrak
Masalah data tidak seimbang merupakan hal yang penting dalam bidang Data Mining. Dataset dengan kelas yang tak seimbang adalah dataset yang frekuensi kejadian dari kelas tertentu sangat jauh berbeda dengan kelas yang lain. Masalah ketidakseimbangan ini akan memberi bias terhadap performa pengklasifikasi. Banyak peneliti telah mengkaji baik berupa pengembangan algoritma maupun modifikasi pada tahap preprocessing untuk mengatasi masalah ini. Pada penelitian ini membahas komparasi algoritma One Class Classification yaitu Elliptic Envelope dan Isolation Forest pada data tidak seimbang. Dari penelitian ini, algoritma Elliptic Envelope menunjukkan hasil lebih baik dibanding dengan algoritma Isolation Forest dengan pengujian recall $80.28 \%$ dan precision $80.28 \%$ sedangkan algoritma Isolation Forest menunjukkan hasil pengujian recall $46.95 \%$ dan precision $46.95 \%$
\end{abstract}

Kata kunci: Data Mining, Data Tidak Seimbang, Klasifikasi, Elliptic Envelope, Isolation Forest

\section{PENDAHULUAN}

Klasifikasi merupakan bagian penting dari Data Mining, klasifikasi akan beroperasi pada data yang diambil dari distribusi yang sama dengan data training. Namun, terdapat juga data yang

${ }^{* 1,2}$ Program Studi Ilmu Komputer Universitas Hasanuddin, Email: supriamir@unhas.ac.id, bagasprasetyo33@gmail.com 


\section{Supri Amir, Bagas Prasetyo}

memiliki jumlah kelas yang tidak seimbang antar kelas yang satu dengan yang lainya disebut imbalanced datasets. Di dalam Machine Learning jika mengunakan pendekatan klasifikasi yang standar, data tidak seimbang menghasilkan performance yang kurang bagus. Kinerjanya yang kurang bagus karena klasifikasi mungkin mengabaikan pentingnya kelas minoritas karena perwakilannya dalam dataset tidak cukup kuat.

Penelitian pada data tidak seimbang merupakan salah satu topik yang menantang pada bidang Machine Learning. Berbagai solusi yang telah diusulkan para peneliti pada masalah ini seperti pengembangan algoritma maupun modifikasi pada tahap preprocessing. Dalam tahap preprocessing berfokus pada menyeimbangkan data (rebalanced dataset). Banyak cara yang telah ditemukan untuk mengatasi dataset tidak seimbang ini, seperti melakukan resampling terhadap data yang ada. Resampling adalah teknik mengambil sampel secara berulang dari sampel data asli. Teknik resampling terdiri dari oversampling, yaitu mengambil sampel berulang kali dari kelas minoritas; dan undersampling, yaitu mengambil sampel secara acak dari kelas mayoritas [1].

Masalah klasifikasi satu kelas (One Class Classification) menjadi sangat penting dalam bidang Machine Learning. Istilah klasifikasi satu kelas telah digunakan oleh Moya dan Hush pada papernya yang berjudul "Network constraints and multi-objective optimization for one-class classification" [4]. Banyak penelitian yang telah dilakukan pada masalah klasifikasi satu kelas dengan aplikasi berbeda, misalnya deteksi outlier/deteksi anomali dan Novelty detection.

Dalam deteksi anomali klasifikasi satu kelas bekerja untuk mengidentifikasi item atau peristiwa tidak terduga dalam kumpulan data, yang berbeda dari data normal. Deteksi anomali memiliki dua asumsi dasar yaitu anomali sangat jarang terjadi dan fitur anomali berbeda dari data normal. Hal ini tidak berbeda dengan pada dataset tidak seimbang dimana anomali sama dengan data minoritas pada dataset tidak seimbang.

Noumir dkk yang mengembangkan sebuah algoritma yang dinamakan One Simple Class Classification pada masalah klasifikasi [5]. Selanjutnya Burnave dkk menggunakan One Class SVM untuk mendeteksi Malware [2].

Satu perbedaan mendasar antara klasifikasi satu kelas dan klasifikasi standar adalah bahwa dalam pembelajaran satu kelas, diasumsikan bahwa hanya informasi kelas target yang tersedia. Dengan kata lain, dalam proses pelatihan classifier, jumlah kelas data dari kelas target digunakan dan tidak ada informasi tentang rekannya. Batas antara kedua kelas harus diperkirakan dari data dari satu-satunya objek yang tersedia.

Menerapkan klasifikasi satu kelas untuk data yang tidak seimbang adalah arah penelitian yang jarang dilakukan, meskipun beberapa pekerjaan telah dilakukan. Meskipun tidak dirancang untuk jenis masalah ini, algoritma klasifikasi satu kelas dapat efektif untuk dataset yang tidak seimbang di mana tidak ada atau sangat sedikit contoh kelas minoritas. Pada penelitian ini dilakukan perbandingan dua algoritma klasifikasi satu kelas yaitu Elliptic Envelope dan Isolation Forest untuk masalah klasifikasi pada data tidak seimbang.

\section{STUDI LITERATUR}

\subsection{Data Tidak Seimbang}

Dataset adalah kumpulan data yang berbentuk tabel, di mana setiap kolomnya merepresentasikan suatu ciri-ciri, atribut atau fitur. Setiap barisnya menyatakan observasi suatu individu, record atau sampel. Suatu dataset biasanya memiliki satu kolom tambahan yang merepresentasikan kelas dari observasi tersebut, kolom ini disebut kolom kelas. Kolom kelas ini juga disebut sebagai variabel dependen terhadap variabel-variabel independen yang merupakan ciri-ciri (atribut) dari suatu observasi tertentu.

Dalam Machine Learning dikenal istilah dataset dengan kelas yang tidak seimbang. Istilah ini berlaku ketika kelas dari dataset tersebut bersifat kategorik diskrit. Dataset dengan kelas yang 


\section{Supri Amir, Bagas Prasetyo}

tidak seimbang (imbalanced class) adalah dataset yang frekuensi kejadian dari kelas tertentu sangat jauh berbeda dengan kelas yang lain. Contohnya seperti suatu dataset dengan jumlah pasien yang berkelas "diabetes" jumlahnya jauh lebih sedikit dibanding pasien yang "tidak diabetes".

Masalah ketidakseimbangan ini akan memberi bias terhadap performa pengklasifikasi sebab jumlah sampel pada kelas tertentu tidak dapat memberi informasi yang cukup kepada pengklasifikasi berdasarkan ciri-ciri yang diberikan [3].

\subsection{Confusion Matrix}

Di dalam Machine Learning, mengukur kinerja atau performa dari suatu model merupakan hal yang esensial. Model yang diperoleh dari pelatihan melalui data training perlu diuji melalui data testing. Kinerja diukur berdasarkan seberapa baik model tersebut memprediksi dengan benar data yang ada.

Pada klasifikasi biner, kelas positif yang berhasil diprediksi dengan benar disebut true positive (TP), jika kelas positif tersebut diprediksi negatif (salah) disebut false negative (FN). Kelas negatif yang berhasil diprediksi negatif (benar) disebut true negative (TN), dan kelas negatif yang diprediksi positif disebut false positive (FP). Jumlah dari kasus-kasus tersebut direpresentasikan dalam suatu tabel 2.1 kontingensi yang disebut confusion matrix.

Tabel 2.1 Confusion Matrix

\begin{tabular}{cccc}
\hline & \multicolumn{3}{c}{ Kelas asli } \\
\hline \multirow{3}{*}{$\begin{array}{c}\text { Hasil } \\
\text { prediksi }\end{array}$} & Positif & Negatif \\
\cline { 2 - 4 } & Positif & TP & FP \\
\cline { 2 - 4 } & Negatif & FN & TN \\
\hline
\end{tabular}

Akurasi (Accuracy) adalah ukuran kinerja yang menunjukkan seberapa baik suatu pengklasifikasi dalam mengklasifikasikan seluruh data. Akurasi adalah rasio antara observasi yang diklasifikasikan secara benar dengan total observasi:

Presisi (Precision) adalah ukuran kinerja yang menunjukkan seberapa besar kebenaran suatu pengklasfikasi dari seluruh kelas positif yang diprediksi. Presisi adalah rasio antara jumlah kelas positif yang diklasifikasikan secara benar dengan jumlah observasi yang diklasifikasikan positif:

$$
\text { Precision }=\frac{T P}{(T P+F P)}
$$

Recall atau sensitivitas adalah ukuran kinerja yang menunjukkan seberapa baik suatu pengklasifikasi dalam mengklasifikasikan kelas positif. Recall adalah rasio antara jumlah observasi positif yang diklasifikasikan secara benar dengan jumlah observasi positif asli:

$$
\text { Recall }=\frac{T P}{(T P+F N)}
$$

F1-Score adalah harmonic mean antara precision dan recall: 


\section{Supri Amir, Bagas Prasetyo}

$$
F 1=2 * \frac{\text { Precision } * \text { Recall }}{(\text { Precision }+ \text { Recall })}
$$

\subsection{Algoritma Klasifikasi Satu Kelas (One Class Classification) \\ 2.3.1 Elliptic Envelope}

Elliptic Envelope adalah fungsi yang mencoba mencari tahu parameter kunci dari distribusi umum data dengan mengasumsikan bahwa seluruh data adalah ekspresi dari distribusi normal/Gaussian multivarian yang mendasarinya. Metode ini mencoba menemukan batas elips sebagian besar data, data yang berada di luar elips akan diklasifikasi sebagai anomali. Elliptic Envelope menggunakan FAST-minimum covariance determinant untuk memperkirakan ukuran dan bentuk elips [6].

FAST-minimum covariance determinat memilih subsampel data yang tidak tumpang tindih dan menghitung mean $(\mu)$, dan kovarians matriks di setiap dimensi fitur dalam subsample. Jarak Mahalobis $\left(d_{M H}\right)$ mengurutkan setiap subsample dan data dari yang terkecil ke yang terbesar. Jarak Mahalobis didefinisikan sebagai

$$
d_{M H}=\sqrt{(x-\mu)^{T} C^{-1}(x-\mu)} \quad 2.4
$$

Jarak Euclidean akan dikurang jika matriks kovarian adalah matriks identitas. Dan jarak Euclidean akan dinormalkan jika matriks kovarian diagonal. Secara sederhana, jarak Mahalobis mengukur berapa banyak sigma titik data dari distribusi mean.

Metode FAST-minimum covariance determinate melanjutkan dengan memilih subsampel dari sampel asli, dengan nilai $d_{M H}$ yang kecil. Mean,kovarian, dan nilai $d_{M H}$ dari subsampel dihitung kembali. Prosedur ini diulang sampai determinasi matriks kovarian menyatu. Matriks kovarians dengan determinasi terkecil dari semua subsampel membentuk sebuah elips yang mencakup sebagian kecil data asli. Data dalam elips diberi label sebagai "inlier"dan data diluar elips diberi label "outlier" atau anomali yang kemudian dapat dihilangkan.

\subsubsection{Isolation Forest}

Algoritma Isolation Forest pada awalnya diusulkan oleh Liu dkk [7]. Algoritma ini berbeda dari kebanyakan algoritma klasifikasi satu kelas lainnya, yang secara eksplisit mengenali anomali/outliers yang dalam penelitian ini disebut kelas minoritas daripada membuat profil data normal yang dalam penelitian ini disebut kelas mayoritas. Secara teoritis, data normal terjadi lebih sering daripada outliers. Selain itu pengamatan untuk data normal dan anomali berbeda satu sama lain dalam hal nilai. Dalam banyak kasus anomali terletak lebih jauh dari titik data biasa dalam satu ruang fitur (gambar 2.2). Berdasarkan fakta ini, titik data anomali memerlukan lebih sedikit partisi untuk diidentifikasi daripada data normal (gambar 2.1). 


\section{Supri Amir, Bagas Prasetyo}

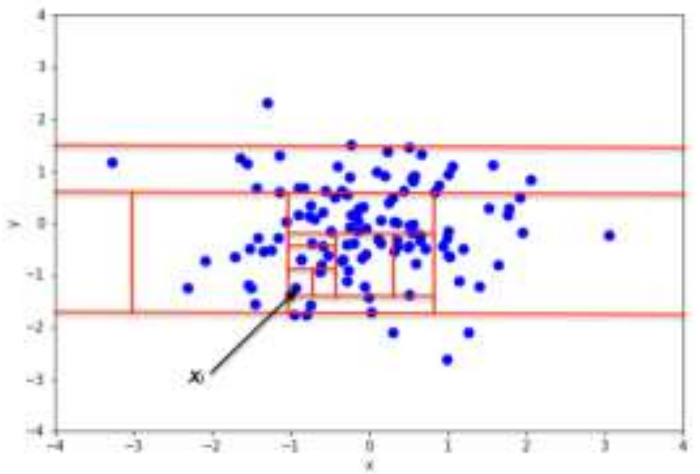

Gambar 2.1. Contoh mengisolasi titk data normal

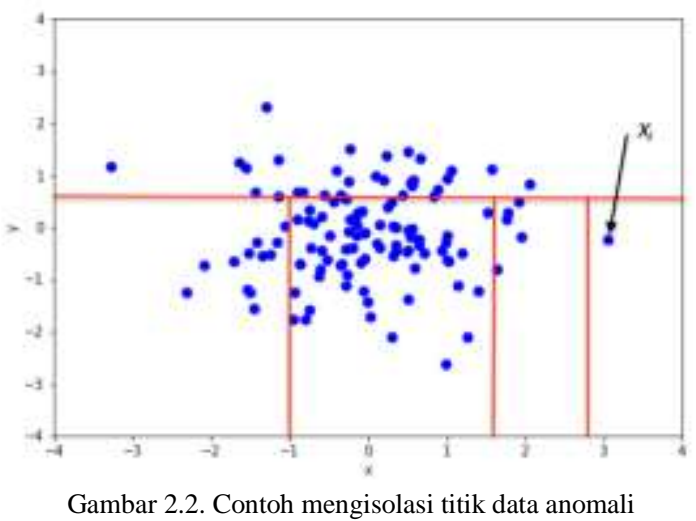

Berdasarkan itu data anomali dalam dataset ada kecenderungan lebih mudah untuk dipisahkan dari sisa sampel, dibandingkan dengan data normal. Dalam rangka untuk mengisolasi titik data, algoritma Isolation Forest secara rekursif menghasilkan partisi pada sampel dengan memilih secara acak atribut dan kemudian secara acak memilih nilai terpisah untuk atribut, antara nilai minimum dan maksimum yang diizinkan untuk atribut tersebut.

Isolation Forest menggunakan skor anomali untuk membuat keputusan. Skor anomali $s$ dari instance $x$ dapat didefinisikan sebagai:

$$
s(x, n)=2^{\frac{E(h(x))}{c(n)}}
$$

Dimana $h(x)$ adalah panjang jalur titik $x, E(h(x))$ adalah rata-rata $h(x)$ dari kumpulan pohon isolasi. $c(n)$ adalah rata-rata panjang jalur pencarian yang tidak berhasil di pohon pencarian biner. $n$ adalah jumlah eksternal node.

\section{METODE PENELITIAN}

\subsection{Deskripsi Data}

Dataset yang digunakan adalah Credit Fraud Dataset yang diperoleh dari website resmi Kagle (https://www.kaggle.com/mlgulb/creditcardfraud) yang terdiri dari 30 kolom attribut dengan 1 kolom kelas, 284.807 baris. 284.315 jumlah sampel kelas mayoritas dan 492 jumlah 


\section{Supri Amir, Bagas Prasetyo}

sampel kelas minoritas dengan imbalanced ratio sebesar 577:1. Dataset ini hanya memiliki 2 kelas yaitu transaksi normal (mayoritas) dan transaksi fraud (minoritas).

\subsection{Tahapan Penelitian}

Penelitian ini melewati beberapa tahap, yaitu :

1. Tahap eksplorasi dan preprocessing data, peneliti mencoba menguraikan karakteristikkarakteristik setiap dataset sebagai informasi untuk mengambil keputusan pada tahap preprocessing. Peneliti akan mengidentifikasi masalah-masalah yang terdapat pada dataset tersebut kemudian mengambil pendekatan untuk menyelesaikan masalah yang terkait. Preprocessing yang akan dilakukan pada data antara lain:

a) Cleaning: pada tahap ini dataset dibersihkan dari missing value, menghilangkan observasi yang tidak diinginkan.

b) Normalisasi: Normalisasi yang akan digunakan yaitu standarscaler yang terdapat pada library sklearn yang berfungsi mengubah data sehingga distribusi data memiliki rata-rata 0 dan standar deviasi 1 .

c) Membagi data: Data akan dibagi menjadi 2 yaitu data training_dan data testing.

2. Tahap model tuning dan fitting, peneliti mencari parameter-parameter terbaik untuk model yang digunakan berdasarkan hasil eksplorasi data dan trial dan error untuk mendapatkan hasil terbaik. Tuning juga dilakukan terhadap beberapa teknik deteksi outlier yang membutuhkan parameter. Kemudian model akan memberi hasil prediksi yang akan dianalisis pada tahap selanjutnya. Algoritma klasifikasi satu kelas yang digunakan pada penelitian ini adalah Elliptic Envelope dan Isolation Forest.

3. Tahap analisis hasil, peneliti akan merangkum hasil yang diperoleh dari algoritma-algoritma yang digunakan ke dalam bentuk tabel dan diagram, kemudian menyimpulkan hasilnya sebagai output dari penelitian ini.

\section{HASIL PEMBAHASAN}

\subsection{Preprocessing}

Pada tahap preprocessing melakukan proses normalisasi pada dataset menggunakan standarscaler yang akan mengubah data sehingga distribusi data memiliki rata-rata 0 dan standar deviasi 1. Proses ini bertujuan untuk memperkecil skala dari dataset tanpa mempengaruhi distribusinya agar memudahkan model belajar lebih cepat dan akurat. Pada tabel 4.1 nilai mean 2 dari 30 atribut data sebelum proses normalisasi dan setelah normalisasi.

\begin{tabular}{ccc}
\multicolumn{2}{c}{ Tabel 4.1. Mean Data Atribut } \\
\hline Atribut & $\begin{array}{c}\text { Mean } \\
\text { sebelum } \\
\text { normalisasi }\end{array}$ & $\begin{array}{c}\text { Mean } \\
\text { setelah } \\
\text { normalisasi }\end{array}$ \\
\hline Amount & 88.291 & 2.91 \\
Time & 94838.20 & -3.06 \\
\hline
\end{tabular}

Setelah itu dilakukan pemberian label 0 untuk transaksi normal dan label 1 untuk transaksi fraud. Kemudian dataset dibagi menjadi 2 bagian yaitu data training dan data testing dengan rasio 70:30. Data training berisi 209315 data transaksi normal dan tidak ada satupun transaksi fraud dalam data training. Data testing berisi 75492 data yang merupakan campuran transaksi normal dan transaksi fraud.

\subsection{Tuning dan Fitting pada Elliptic Envelope}




\section{Supri Amir, Bagas Prasetyo}

Proses dalam menentukan parameter pada metode disebut proses tuning. Parameter untuk algoritma Elliptic Envelope adalah support fraction dan untuk nilai awal support fraction yang digunakan pada penelitian ini adalah 0.994 .

Model akan dibuat berdasarkan data training dan hasil model tersebut akan melalui proses data testing atau disebut fitting. Kemudian akan dilakukan perulangan pada proses tuning dan fitting hingga parameter terbaik didapatkan berdasarkan nilai skor F1. Pada tabel 4.2 adalah hasil pencarian parameter terbaik untuk metode Elliptic Envelope.

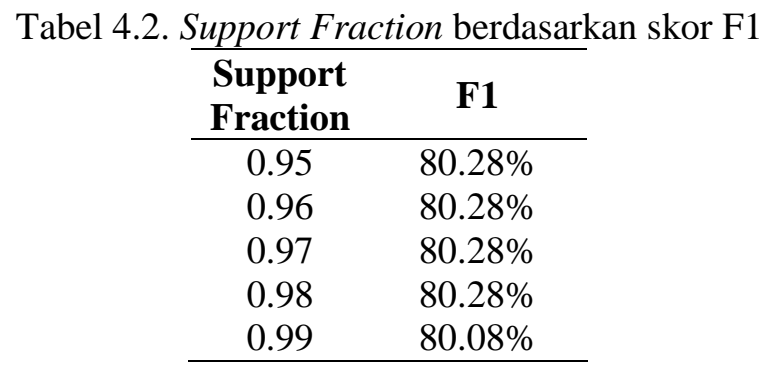

Diperoleh nilai 0.95 sampai 0.98 memiliki hasil skor F1 yang sama. Jadi nilai support fraction yang akan digunakan pada algoritma Elliptic Envelope adalah 0.95.

\subsection{Tuning dan Fitting pada Isolation Forest}

Parameter untuk algoritma Isolation Forest adalah num estimator dan untuk nilai awal num estimator yang digunakan pada penelitian ini adalah 1050. Setelah itu model akan dibuat berdasarkan data training dan hasil model tersebut akan di test pada data testing atau disebut fitting. Pada tabel 4.3 adalah hasil pencarian parameter terbaik untuk algoritma Isolation Forest.

Tabel 4.3. Num estimator berdasarkan skor F1

\begin{tabular}{cc}
\hline $\begin{array}{c}\text { Num } \\
\text { estimator }\end{array}$ & F1 \\
\hline 900 & $46.34 \%$ \\
950 & $46.54 \%$ \\
1000 & $46.95 \%$ \\
1050 & $46.95 \%$ \\
1100 & $46.95 \%$ \\
\hline
\end{tabular}

Didapatkan nilai 1000 sampai 1100 memiliki hasil skor F1 terbaik. Sehingga nilai Num estimator yang akan digunakan pada algoritma Isolation Forest adalah 1000.

\subsection{Hasil perbandingan}

Penelitian ini membandingkan dua algoritma yaitu Elliptic Envelope dan Isolation Forest pada masalah klasifikasi pada data tidak seimbang. Penelitian ini membandingkan recall, precision dan $F 1$ dari hasil klasifikasi algoritma tersebut. Nilai yang akan di perbandingkan merupakan parameter terbaik yang didapat berdasarkan skor F1 masing-masing metode seperti yang ditunjukkan pada tabel 4.4 


\section{Supri Amir, Bagas Prasetyo}

Tabel 4.4. Hasil Perbandingan Recall, Precision, dan skor F1

\begin{tabular}{cccc}
\hline Metode & Recall & Precision & F1 \\
\hline $\begin{array}{c}\text { Elliptic } \\
\text { Envelope }\end{array}$ & $80.28 \%$ & $80.28 \%$ & $80.28 \%$ \\
$\begin{array}{c}\text { Isolation } \\
\text { Forest }\end{array}$ & $46.95 \%$ & $46.95 \%$ & $46.95 \%$ \\
\hline
\end{tabular}

\section{KESIMPULAN}

Dari hasil percobaan terbukti bahwa algoritma klasifikasi satu kelas yang lebih baik kinerjanya pada klasifikasi dataset tidak seimbang adalah Elliptic Envelope dibandingkan Isolation Forest. Algoritma Elliptic Envelope menunjukkan hasil pengujian recall $80.28 \%$ dan precision $80.28 \%$ sedangkan Isolation Forest menunjukkan hasil pengujian recall $46.95 \%$ dan precision $46.95 \%$

\section{DAFTAR PUSTAKA}

[1] Burnaev, E., Erofeev, P. and Papanov, A., (2015). Influence of resampling on accuracy of imbalanced classification. Eighth International Conference on Machine Vision (ICMV 2015), 9875(December), p.987521.

[2] Burnaev, E. and Smolyakov, D., (2016). One-Class SVM with Privileged Information and Its Application to Malware Detection. IEEE International Conference on Data Mining Workshops, ICDMW, 0, pp.273-280.

[3] Kang, S. and Ramamohanarao, K., (2014). A robust classifier for imbalanced datasets. Lecture Notes in Computer Science (including subseries Lecture Notes in Artificial Intelligence and Lecture Notes in Bioinformatics), 8443 LNAI(PART 1), pp.212-223.

[4] Moya, M.M. and Hush, D.R., (1996). Network constraints and multi-objective optimization for one-class classification. Neural Networks, 9(3), pp.463-474.

[5] Noumir, Z., Honeine, P. and Richard, C., (2012). On simple one-class classification methods. IEEE International Symposium on Information Theory - Proceedings, (October), pp.2022-2026.

[6] Rousseeuw, P. and Driessen, K., (1999). A Fast Algorithm for the Minimum Covariance. Technometrics, 41(3), pp.212-223.

[7] Tony Liu, F., Ming Ting, K. and Zhou, Z.-H., (2008). Isolation Forest ICDM08. Icdm. 